\title{
Antibacterial properties of extracts of Solidago canadensis and their potential use as dietary supplements in red swamp crayfish (Procambarus clarkii)
}

\author{
Manhong YE ${ }^{1}$, Lei ZHANG ${ }^{1}$, Jiaqi GE ${ }^{1}$, Haifeng SUN ${ }^{1}$, Jingjing NI $^{1}$, Shengmei YANG ${ }^{2}$, Wanhong WEI (ه) ${ }^{1}$ \\ 1 College of Bioscience and Biotechnology, Yangzhou University, Yangzhou 225000, China \\ 2 Jiangsu Co-innovation Center for Prevention and Control of Important Animal Infectious Diseases and Zoonoses, \\ Yangzhou University, Yangzhou 225000, China
}

\begin{abstract}
Canadian goldenrod (Solidago canadensis) is one of the most destructive invasive weeds in Southeastern China. To evaluate its potential application as dietary supplement in red swamp crayfish (Procambarus clarkii), the antibacterial properties of aqueous and ethanol extracts of this plant against three major pathogenic bacteria in crayfish aquaculture were examined. Inhibition zone tests and determination of minimum inhibitory concentration revealed that the extracts had lower antibacterial activity than extracts from two traditional medicinal plants that possess antibacterial properties, garlic (Allium sativum) and cortex phellodendri (Phellodendron chinense). However, they did exhibit greater antibacterial effects than extracts from another widely used medicinal plant, Sophora flavescens, and an aquatic weed, Alternanthera philoxeroides. Aqueous extracts of Canadian goldenrod gave greater inhibition than the ethanol extracts. Crayfish fed a diet with $2 \%$ these aqueous extracts exhibited significantly higher enzyme activity of alkaline phosphatase, catalase and phenoloxidase $(P<0.05)$. Based on the results of this study, we conclude that aqueous extracts of Canadian goldenrod are highly promising for the development of new dietary supplement for use in crayfish aquaculture.
\end{abstract}

Keywords antibacterial activity, Canadian goldenrod, antioxidant enzyme, crayfish

Received July 24, 2015; accepted November 13, 2015

Correspondence: whwei@yzu.edu.cn

\section{Introduction}

Bacterial species from numerous Gram-negative genera including Aeromonas and Vibrio can cause asymptomatic bacteremia and bacterial septicemia in freshwater crayfish, with the former condition representing an early phase of the latter. Aeromonas is one of the most frequently reported asymptomatic genera that have been isolated from the hemolymph of apparently healthy crayfish ${ }^{[1]}$. Ingestion of food contaminated with Aeromonas hydrophila and Aeromonas veronii bv. Sobria has been frequently reported to cause gastrointestinal diseases in human ${ }^{[2]}$. While the abundance of Vibrio species can lead to the development of vibriosis in crayfish, Vibrio parahemolyticus is also of great concern for food safety because it is recognized as a human pathogen and is a leading cause of food poisoning especially in Asian countries ${ }^{[3]}$. With the growth of intensive crayfish aquaculture, the occurrence of disease outbreaks caused by these bacteria is likely to increase and the consumption of food contaminated with A. hydrophila, $A$. veronii bv. Sobria and $V$. parahemolyticus involves a great risk to public health. The development of safe therapeutants and the implementation of effective disease control methodologies are urgent requirements not only for the crayfish culture system but also for consumers.

In China, red swamp crayfish (Procambarus clarkii) was introduced for human consumption in the early 1940s and is now the most common freshwater crayfish eaten. To defend crayfish against pathogens, the implementation of preventive and control strategies always involves pesticides, disinfectants, and antimicrobial drugs and their use has been growing in parallel with the development of aquaculture. However, there is now worldwide concern that the use of such products represents an increasing risk for human health and for the sustainable use of aquatic 
environments ${ }^{[4-6]}$. In this regard, studies on the development of alternative feed additives, such as oligosacchar$\operatorname{ide}^{[7]}$, emodin ${ }^{[8]}$, cornstarch ${ }^{[9]}$ and L-carnitine ${ }^{[10]}$, to stimulate the crayfish immune system and protect them from different stressors, have been undertaken. Plant extracts have received special attention as biologicallyactive feed additives and growth enhancers and have been suggested as potential alternatives for disease control in aquaculture. However, limited research on such additives has been reported for crayfish.

Canadian goldenrod (Solidago canadensis), a perennial composite native to North America, was introduced into China as a horticultural plant in the early 1930s and has become naturalized in Shanghai, Jiangsu and Zhejiang. Since the 1980s, it has spread rapidly as an exotic invasive weed. In colonized areas, it significantly reduces overall species abundance and diversity, and has caused serious damage to agricultural production and ecosystems ${ }^{[11]}$. Its high adaptability to various environments ${ }^{[12]}$, rampant reproductive capacity in response to disturbance ${ }^{[13]}$, and the absence of natural herbivores makes it one of the most destructive invasive weeds in south-eastern China. To date, there has been no research on the effects of extracts from Canadian goldenrod on the nonspecific immune system of crayfish. The aim of the present study was to evaluate the antimicrobial activity of extracts from Canadian goldenrod as well as the side effects of its dietary supplementation on the antioxidant status of adult red swamp crayfish using superoxide dismutase (SOD), catalase (CAT), alkaline phosphatase (AKP), acid phosphatase (ACP) and phenoloxidase (PO) activities as biological indices.

\section{Materials and methods}

\subsection{Plant material}

Canadian goldenrod (S. canadensis) and Alternanthera philoxeroides were collected from Shugang ridge in the Slender West Lake Park, Yangzhou, China in the month of September. Garlic (Allium sativum) was purchased from a farmer's market. Phellodendron chinense and Sophora flavescens were purchased from a traditional Chinese medicine dispensary. Plant materials were washed under running tap water followed by sterilized distilled water, airdried in the shade for 30 days and then powdered with the help of a sterilized pestle and mortar. The ground powders were kept in airtight bags separately at room temperature before use.

\subsection{Plant extracts}

The aqueous extracts were prepared by decocting dried plants with boiling distilled water $\left(50 \mathrm{~g} \cdot \mathrm{L}^{-1}\right)$ for $1 \mathrm{~h}$. The hot decoction was first filtered through four layers of gauze, and then filtered with syringe filters (Millex-LH,
$0.45 \mu \mathrm{m}$ pore size, Millipore, Billerica, MA, USA). The filtrates were then evaporated using a rotary evaporator (R5003K2B, Shanghai SENCO Technology Co. Ltd., China) to give a concentrated extract.

The ethanol used in this experiment for extraction was of analytic grade and purchased from Sinopharm Chemical Reagent Co. Ltd. (Shanghai, China). Fifty gram of airdried and powered plants were first soaked in $1 \mathrm{~L}$ ethanol for $24 \mathrm{~h}$ at room temperature and then homogenized completely by electromagnetic stirring for $1 \mathrm{~h}$. The solution was centrifuged $(3000 \times g$ for $5 \mathrm{~min})$ and the supernatant then collected and filtered through $0.45 \mu \mathrm{m}$ syringe filters. Extraction was repeated on the residues three times using the same method, and all supernatants combined and blended. The combined extract was rotary evaporated to dryness under reduced pressure at $40^{\circ} \mathrm{C}$. Both aqueous and ethanol extracts were stored at $-20^{\circ} \mathrm{C}$ until use. Extract yields were determined dividing the weight of extract by the original weight of ground sample.

\subsection{Antimicrobial screening}

\subsubsection{Microorganisms}

Three Gram-negative bacteria, biochemically and morphologically identified as A. hydrophila, A. veronii bv. Sobria and $V$. parahemolyticus were used. A. hydrophila and $A$. veronii bv. Sobria were provided by the Freshwater Fisheries Research Institute, Jiangsu, China. V. parahemolyticus was obtained from the Zoonosis Laboratory, Yangzhou University, Jiangsu, China. They were maintained on nutrient agar slants. Each of the microorganisms was subcultured before susceptibility testing by transferring them into a separate test tube containing nutrient broth and incubated overnight at $28^{\circ} \mathrm{C}$.

\subsubsection{Turbidity measurement}

Four to five colonies from an agar plate culture grown overnight were inoculated into $5 \mathrm{~mL}$ of the beef extractpeptone medium. After incubating at $28^{\circ} \mathrm{C}$ and shaking at $200 \mathrm{r} \cdot \mathrm{min}^{-1}$ for $18 \mathrm{~h}, \mathrm{McF}$ arland standards were used to estimate the cell concentration and assess the approximate number of bacteria. The bacterial suspensions were visually adjusted with broth to a 0.5 McFarland standard, which corresponded to $1.5 \times 10^{8}$ colony forming units (CFU) per milliliter.

\subsubsection{Agar well diffusion method}

The antibacterial activity of the extracts was determined by the Kirby-Bauer method of agar well diffusion ${ }^{[14]}$. Briefly, A. hydrophila, A. veronii bv. Sobria and V. parahemolyticus were subcultured in the beef extract-peptone medium at $28^{\circ} \mathrm{C}$ for about $18 \mathrm{~h}$ in an incubator and adjusted to a 
turbidity of 0.5 McFarland standard. Then agar plates of the beef extract-peptone media were prepared. Each plate was inoculated by spreading bacterial suspension $\left(10^{8} \mathrm{CFU} \cdot \mathrm{mL}^{-1}\right)$ evenly on the surface of solid agar media with the help of a cotton swab. Plates were then air-dried at room temperature for $20 \mathrm{~min}$ and then 6-mm-diameter wells, equidistant from one another and from the dish edge, were punched in the agar, four wells per dish. Extracts were dissolved separately in dimethyl sulfoxide (DMSO) to a stock concentration of $200 \mathrm{mg} \cdot \mathrm{mL}^{-1}$ and then diluted to the working concentrations of $50,75,100,125$ and $150 \mathrm{mg} \cdot \mathrm{mL}^{-1}$. Each well received $50 \mu \mathrm{L}$ solution extracts. The negative control wells were filled with $50 \mu \mathrm{L}$ DMSO only. All the plates were incubated in a thermostat at $28^{\circ} \mathrm{C}$ for $18 \mathrm{~h}$. After incubation, the resulting inhibition zones were measured to an accuracy of $\pm 0.1 \mathrm{~mm}$. The mean inhibition-zone diameter was calculated. All experiments were repeated three times.

\subsubsection{Estimation of minimum inhibitory concentration}

The minimum inhibitory concentration (MIC) of all plant extracts was determined using the standard agar dilution method. Each extract was first dissolved in DMSO to the stock concentration of $200 \mathrm{mg} \cdot \mathrm{mL}^{-1}$. Then serial twofold extracts dilutions were prepared using DMSO at concentrations of $12.5,25,50$ and $100 \mathrm{mg} \cdot \mathrm{mL}^{-1}$. After mixing 1 $\mathrm{mL}$ plant extract solution with $19 \mathrm{~mL}$ sterile beef extractpeptone agar (cooled to $50^{\circ} \mathrm{C}$ ) plates $(90 \mathrm{~mm}$ in diameter) were poured containing various concentration of plant extracts $\left(0.625,1.25,2.5,5\right.$ and $\left.10 \mathrm{mg} \cdot \mathrm{mL}^{-1}\right)$. Three bacterial species were grown to the early logarithmic phase in beef extract-peptone medium at $28^{\circ} \mathrm{C}$. Each species was adjusted to a $0.5 \mathrm{McF}$ arland standard and diluted 10 times before inoculation. All plates except those acting as sterility controls were inoculated with $1 \mu \mathrm{L}$ bacterial suspension containing approximately $10^{7} \mathrm{CFU}$. After the bacteria suspensions were absorbed completely onto the medium, plates were incubated at $28^{\circ} \mathrm{C}$ for $18 \mathrm{~h}$ in stacks of less than two layers to ensure appropriate humidity and air circulation. Plates with bacteria growing on solid medium containing a corresponding amount of DMSO and without any plant extracts were set as negative controls. The MIC determinations were independently repeated three times. The MIC for each species was determined as the highest dilution at which there was no apparent growth.

\subsection{Feeding trial}

All animal experiments were performed in accordance with the recommendations in the Guide for the Care and Use of Laboratory Animals of China. Healthy red swamp crayfish (P. clarkii), about 15 to $20 \mathrm{~g}$ each, were collected with Dshaped dip nets from crayfish culture ponds at the
Freshwater Fisheries Research Institute, Jiangsu, China. Immediately after collection, groups of crayfish were transported to the laboratory and acclimated for 7 days in aerated tap water at ambient temperature of $25 \pm 1^{\circ} \mathrm{C}$ under a natural day-night cycle. Ten crayfish were maintained in a single glass tank $(1 \mathrm{~m} \times 0.5 \mathrm{~m} \times 0.5 \mathrm{~m})$ supplied with continuous aeration to ensure that the dissolved oxygen concentration was greater than $6 \mathrm{mg} \cdot \mathrm{L}^{-1} \mathrm{O}_{2}$. Commercial crab pellets, containing $32 \%$ of crude protein, $3 \%$ crude fat, $7 \%$ crude fiber, $17 \%$ crude ash, $1 \%-2 \%$ calcium, $1 \%$ total phosphate, $12.5 \%$ water and $1.6 \%$ lysine, were purchased from Tongwei Feedstuff Co. Ltd., Suzhou, Jiangsu, China. During the acclimation period, the crayfish were fed twice daily to satiation at 6 am and $6 \mathrm{pm}$. Uneaten food was collected by siphoning and half of the tank water was replaced with aerated tap water $(\mathrm{pH} 7.0-7.2)$ each afternoon before feeding.

Aqueous extracts from the six test plants were used as dietary supplements. Crayfish in the control group were fed with the commercial diet. Aqueous extracts from plants were supplemented to the basal diet to formulate experimental diets containing $2 \%(\mathrm{~W} / \mathrm{W})$ of plant extracts. Briefly, dry basal diets ground through a $60-\mathrm{mm}$ mesh, aqueous extracts from plants and an appropriate amount of water were thoroughly mixed to form a stiff dough. The dough was then made into $1 \mathrm{~mm}$ diameter pellets by means of a laboratory extrusion machine, oven-dried at $60^{\circ} \mathrm{C}$ and stored at $-20^{\circ} \mathrm{C}$ until used.

\subsection{Sample collection}

A total of 420 acclimated crayfish were randomly allocated to six test groups and one control group and distributed into 42 tanks. On day 3, 7, 14 and 21 of the trial, five crayfish were randomly removed from each group for hemolymph collection. Hemolymph was obtained by pericardial cavity puncture (20-gauge needle) and transferred via capillary tube into a microcentrifuge tube. Samples were placed immediately on ice, allowed to clot, stored at $4^{\circ} \mathrm{C}$ overnight and then centrifuged $(4000 \times g$ for $20 \mathrm{~min}$ at $4^{\circ} \mathrm{C}$ ) to extract the supernatant serum. Hepatopancreases were subsequently removed and the dissected tissues were homogenized with a blender using 10 volume ice-cold potassium phosphate buffer ( $\mathrm{pH} 6.4$, $0.1 \mathrm{~mol} \cdot \mathrm{L}^{-1}$ ). Cell debris was removed by centrifuging at $8000 \times g$ for $20 \mathrm{~min}$ and the supernatants from the crude tissue samples prepared for subsequent determination of enzyme activity.

\subsection{Determination of enzyme activity}

The activity of total SOD (superoxide dismutase), CAT (catalase), AKP (alkaline phosphatase) and ACP (acid phosphatase) was spectrophotometrically measured using commercial enzyme assay kits (A001-1, A005, A059-1 
and A060-1 from Nanjing Jiancheng Bioengineering Institute, Nanjing, Jiangsu, China) in accordance with the manufacturer's instructions. The total protein content was estimated by the method of Bradford ${ }^{[15]}$ using bovine serum albumin as standard.

Phenoloxidase (PO) activity was measured spectrophotometrically by monitoring the rate of formation of dopachrome from L-3,4-dihydroxyphenylalanine (LDOPA, Sigma-Aldrich, St. Louis, MO, USA) as previously described $^{[16]}$. Some modifications were made in order to make sure that the absorbance lay between 0.1 and 1.0. Briefly, $3 \mathrm{~mL}$ phosphate buffer solution $\left(0.1 \mathrm{~mol} \cdot \mathrm{L}^{-1}\right.$, pH 6.0), $100 \mu \mathrm{L} \mathrm{L-DOPA}\left(0.01 \mathrm{~mol} \cdot \mathrm{L}^{-1}\right)$ and $100 \mu \mathrm{L}$ serum were mixed completely and kept at $25^{\circ} \mathrm{C}$ in water bath for $10 \mathrm{~min}$. The optical density (OD) was measured at $2 \mathrm{~min}$ intervals for $10 \mathrm{~min}$ at $490 \mathrm{~nm}$. One unit of enzyme activity was defined as an increase in absorbance of 0.001 per minute per milliliter serum.

\subsection{Statistical analysis}

Statistical analysis was performed with the SPSS 13.0 software package. All data were subjected to one-way analysis of variance. Significant differences were determined at the $0.05 \%$ probability level, the Fisher's Least Significant Difference then used to identify significant differences among different groups.

\section{Results}

\subsection{In vitro antibacterial assay}

The antibacterial activity of plant extracts against three Gram-negative bacteria is shown in Fig. 1. These results reveal that A. sativum extracts exhibited the strongest antibacterial effects against tested microorganisms followed by $P$. chinense. When concentrations of the aqueous and ethanol extracts were higher than $50 \mathrm{mg} \cdot \mathrm{mL}^{-1}$, the highest inhibition was always observed in extracts from $A$. sativum, which was demonstrated by the significantly larger diameters of inhibition zones. The only exception was that at a concentration of $75 \mathrm{mg} \cdot \mathrm{mL}^{-1}$, aqueous extracts from $A$. sativum and $P$. chinense had the same antibacterial activity against $A$. hydrophila. At the concentration of $50 \mathrm{mg} \cdot \mathrm{mL}^{-1}$, extracts from $A$. sativum had either significantly higher or equal antibacterial effects to those from $P$. chinense with the exception that aqueous extracts from $P$. chinense had a significantly larger diameter of inhibition zone against $V$. parahemolyticus than $A$. sativum extracts. These findings are consistent with the fact that $A$. sativum and $P$. chinense are commonly recognized as medicinal plants with various antimicrobial activities.

The antibacterial activity of aqueous extracts was highest for A. sativum, and decreased in the order $P$. chinense, then $S$. canadensis, A. philoxeroides and finally $S$. flavescens. However, no obvious trend could be detected for ethanol extracts, except that ethanol extracts from $A$. sativum had significantly higher antibacterial activity than those from any other plants. Interestingly, the water extracts from $S$. canadensis were more effective than ethanol extracts.

Determination of MIC revealed that in most cases, extracts from A. sativum and $P$. chinense were equivalent in antibacterial activity with similar MIC (Table 1). Ethanol extracts from $A$. sativum had relatively higher antibacterial activity against $A$. hydrophila and $A$. veronii bv. Sobria $\left(\mathrm{MIC}=2.5 \mathrm{mg} \cdot \mathrm{mL}^{-1}\right)$ than those from $P$. chinense $(\mathrm{MIC}=$ $5 \mathrm{mg} \cdot \mathrm{mL}^{-1}$ ). These results were consistent with those obtained in the inhibition zone test. S. canadensis showed moderate antibacterial activity against the test bacteria followed by extracts from $S$. flavescens. Extracts from $A$. philoxeroides showed the lowest activity against the three test bacteria with MIC larger than $10 \mathrm{mg} \cdot \mathrm{mL}^{-1}$.

\subsection{Enzyme activity in serum and hepatopancreas}

Although extracts from $A$. sativum and $P$. chinense exhibited promising antibacterial activity against the three commonly found bacteria in crayfish aquaculture, the addition of aqueous extracts from these two plants as dietary ingredients in crayfish did not give rise to significant elevation of any enzyme activity studied in serum or hepatopancreas. Compared to the control animals, significantly higher enzyme activity was only observed at two time points, day 14 and 21, in crayfish supplemented with aqueous extracts from $P$. chinense, which was CAT activity in the hepatopancreas $(17.7 \pm 2.2$ vs. $9.8 \pm 1.6 \mathrm{U}$ per milligram protein) and $\mathrm{PO}$ activity in the serum ( $1.4 \pm 0.1$ vs. $0.7 \pm 0.1 \mathrm{U}$ per milligram protein).

In contrast, crayfish fed with aqueous extracts from $S$. canadensis exhibited significantly higher enzyme activity in serum and hepatopancreas tissue than the control group at some time points (Table 2). These results indicate that day 7 was crucial for the effect of $S$. canadensis supplement on the AKP activity. At this time point both the hepatopancreas and serum AKP levels were the highest. Addition of aqueous extracts from $S$. canadensis also resulted in significantly higher activity of CAT in the hepatopancreas. Notably, the CAT activity showed a significant decrease on day 7 before it increased again on day 14 then remained at the higher level till day 21 . The influence of dietary $S$. canadensis on the PO activity followed a different trend. A significant increase of PO activity was observed only on day 3 . From day 7 till the end of the experiment, no significant difference in PO activity was detected between the $S$. canadensis and control groups. However, on day 21, when the PO activity in the serum of the control animals decreased to half of the 

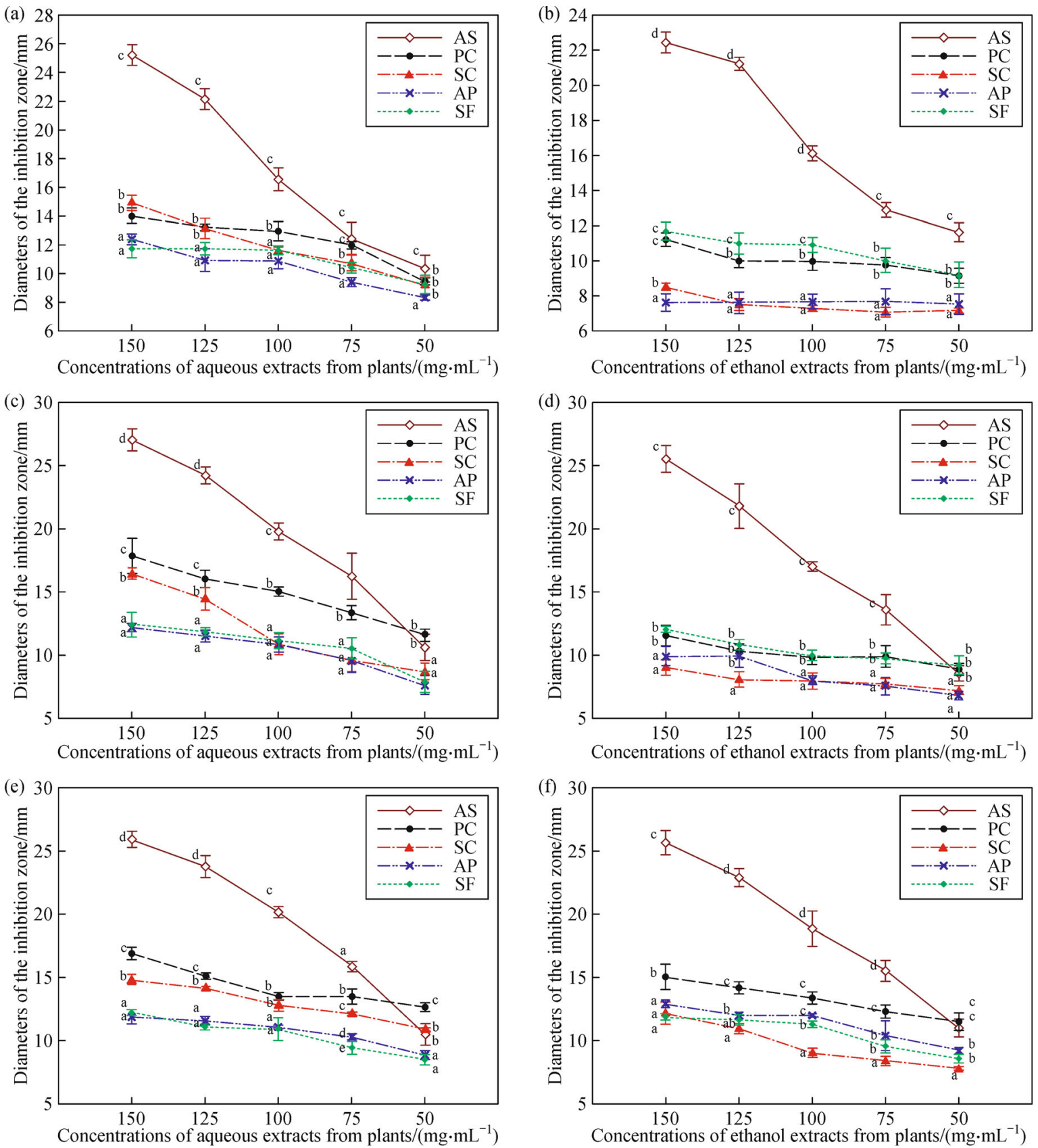

Fig. 1 Results of the agar well diffusion assay. (a, b) Plant extracts against Aeromonas hydrophila; (c, d) plant extracts against A. veronii bv. Sobria; (e, f) plant extracts against Vibrio parahaemolyticus. Data are presented as mean \pm SE. The diameters of the inhibition zone were compared between plant extracts at the same concentration. The same superscripted letters indicate no difference, and the different superscript letters indicate significant difference $(P<0.05)$ among different plant extracts. AS, Allium sativum; PC, Phellodendron chinense; SC, Solidago canadensis; AP, Alternanthera philoxeroides; SF, Sophora flavescens.

Table 1 Minimum inhibitory concentrations

\begin{tabular}{|c|c|c|c|c|c|c|c|c|c|c|}
\hline \multirow{2}{*}{ Bacteria } & \multicolumn{5}{|c|}{ Aqueous extracts } & \multicolumn{5}{|c|}{ Ethanol extracts } \\
\hline & AS & $\mathrm{PC}$ & $\mathrm{SC}$ & AP & SF & AS & $\mathrm{PC}$ & $\mathrm{SC}$ & AP & SF \\
\hline Aeromonas hydrophila & 5.0 & 5.0 & 5.0 & $>10$ & 10 & 2.5 & 5.0 & 10 & $>10$ & 10 \\
\hline Aeromonas veronii bv. Sobria & 2.5 & 2.5 & 5.0 & $>10$ & 10 & 2.5 & 5.0 & 10 & $>10$ & 10 \\
\hline Vibrio parahemolyticus & 2.5 & 2.5 & 5.0 & $>10$ & 10 & 5.0 & 5.0 & 10 & $>10$ & 10 \\
\hline
\end{tabular}

Note: AS, Allium sativum; PC, Phellodendron chinense; SC, Solidago canadensis; AP, Alternanthera philoxeroides; SF, Sophora flavescens. 
value of day 14, crayfish in the $S$. canadensis group still had about the same level of PO activity. These preliminary results provided the first evidence of the potential activity of aqueous extracts from $S$. canadensis in maintaining the crayfish enzyme activity at a relatively high level, which was supported by the change of serum AKP and PO level on day 21.

During the experiment, sporadic elevation in enzyme activity in crayfish supplemented with $S$. flavescens was also observed, such as serum AKP level $(3.7 \pm 0.7$ vs. $1.7 \pm 0.3 \mathrm{U}$ per milligram protein) on day 7 and CAT level in the hepatopancreas $(21.7 \pm 4.4$ vs. $9.8 \pm 1.6 \mathrm{U}$ per milligram protein) on day 14 . In most cases, enzyme activity in crayfish in the group supplemented with $A$. philoxeroides was lower than in the control group (data not shown).

\section{Discussion}

Crayfish constitute an important commodity in aquaculture, have direct and indirect value for humans, and are important in ecosystems ${ }^{[17,18]}$. A range of fungal, viral and bacterial pathogens can cause various diseases in crayfish, which were partly related to the exposure to environmental stresses, such as elevated temperature, low dissolved oxygen and increasing holding time in tanks under unfavorable conditions ${ }^{[19,20]}$. With increasing sales of crayfish for human consumption in China, the development of health-improving natural feed additives in crayfish diet is important for increasing the profitability and sustainability of crayfish aquaculture.

It is well known that crude extracts from plants can contain a mixture of several active substances which may have different antimicrobial effects in animals, and thus reduce the occurrence of resistant pathogen populations ${ }^{[21]}$. The use of plants extracts for limiting infections in this way is usually considered to be safe and beneficial. The use of Canadian goldenrod for the treatment of chronic nephritis, cystitis, urolithiasis, rheumatism and as an antiphlogistic drug has a history of more than 700 years in European phytotherapy ${ }^{[22]}$. It was also used by indigenous people in North America for the treatment of diabetes mellitus ${ }^{[23]}$. However, its application as a dietary supplement in crayfish diet has not been documented.

In this study, we identified the antibacterial activity of Canadian goldenrod extracts against three bacteria commonly found in crayfish culture systems. Our results indicated that their antibacterial effects were significant although less than extracts from $A$. sativum and $P$. chinense, two plants with numerous therapeutic effects in herbal medicine ${ }^{[24-26]}$, and were stronger than A. philoxeroides and $S$. flavescens extracts. Since the continuous use of antimicrobials will increase bacterial resistance, our results indicate the potential use of Canadian goldenrod extracts as an environmentally safe control measure for these bacteria in the intensive crayfish production.

The activity of two biomarkers of oxidative stress (SOD and CAT), one immune factor (PO), and two important enzymes involved in metabolic regulation (ACP and AKP), were also determined in this study. This appears to be the first report of aqueous extracts from Canadian goldenrod enhancing PO, CAT, and AKP activity in adult crayfish. The significantly higher activity of these enzymes indicated lowered lipid peroxidation, improved resistance to oxidative stress, and reduced risk of immunosuppression in crayfish ${ }^{[27]}$. Since oxidative stress is known to be linked to many diseases, these results demonstrate that aqueous extracts from Canadian goldenrod might be a beneficial dietary supplement for improving the performance of crayfish under suboptimal conditions and with bacterial exposure.

Compared with crayfish in the control group, no significant change of enzyme activity was detected in crayfish treated with aqueous extracts from $A$. sativum and $P$. chinense. The most likely explanation is that the extract procedure, including selection of plant part and collecting protocol, significantly affects active principles in crude extracts. Although the antioxidant activity of aqueous extracts from Canadian goldenrod may come from various

Table 2 Significant change of enzyme activity in crayfish supplemented with aqueous extracts from Canadian goldenrod compared with a control group

\begin{tabular}{|c|c|c|c|c|c|c|}
\hline \multirow{2}{*}{ Tissues } & \multirow{2}{*}{$\begin{array}{c}\text { Enzyme activity } \\
\text { (U per milligram protein) }\end{array}$} & \multirow{2}{*}{ Groups } & \multicolumn{4}{|c|}{ Experimental day } \\
\hline & & & Day 3 & Day 7 & Day 14 & Day 21 \\
\hline \multirow[t]{4}{*}{ Hepatopancreas } & AKP & Control & $24.2 \pm 3.5$ & $41.3 \pm 9.4$ & $30.4 \pm 3.0$ & $39.5 \pm 5.4$ \\
\hline & & $\mathrm{SC}$ & $33.5 \pm 7.7$ & $69.8 \pm 13.7 *$ & $24.4 \pm 7.7$ & $38.4 \pm 1.7$ \\
\hline & CAT & Control & $15.9 \pm 2.2$ & $19.0 \pm 2.5$ & $9.8 \pm 1.6$ & $13.9 \pm 4.7$ \\
\hline & & $\mathrm{SC}$ & $18.9 \pm 2.5$ & $10.1 \pm 1.8^{*}$ & $21.0 \pm 2.8^{*}$ & $21.3 \pm 3.5^{*}$ \\
\hline \multirow[t]{4}{*}{ Serum } & AKP & Control & $1.5 \pm 0.2$ & $1.7 \pm 0.3$ & $4.2 \pm 1.5$ & $1.5 \pm 0.04$ \\
\hline & & $\mathrm{SC}$ & $1.5 \pm 0.4$ & $5.7 \pm 1.0 *$ & $2.6 \pm 0.6$ & $2.6 \pm 0.6$ \\
\hline & $\mathrm{PO}$ & Control & $1.6 \pm 0.5$ & $1.4 \pm 0.2$ & $1.4 \pm 0.7$ & $0.7 \pm 0.1$ \\
\hline & & $\mathrm{SC}$ & $2.7 \pm 0.3^{*}$ & $1.0 \pm 0.3$ & $1.3 \pm 0.3$ & $1.3 \pm 0.1$ \\
\hline
\end{tabular}

Note: AKP, alkaline phosphatase; CAT, catalase; PO, phenoloxidase; SC, Solidago canadensis; *, significant difference $(P<0.05)$. 
substances, such as antioxidant vitamins, phenolics or tannins, our observations did show that the extraction method used resulted in efficient dissolution of functional compounds from crude plant powder. Further study on the physiological functions of these extracts is needed to determine their most appropriate use before they can be approved as dietary antioxidants. Also, their synergistic antioxidant effects in combination with other aqueous extracts from plants needs further study. With the development of intensive aquaculture, water pollution, underlying environmental conditions and frequent occurrence of diseases have resulted in economic losses in crayfish production, and natural compounds with antioxidant properties, and without the toxic side effects of synthetic antioxidants, are becoming the most promising dietary immunoenhancers. The strategy of using aqueous extracts from Canadian goldenrod as a dietary supplement in crayfish culture systems will improve the production of crayfish and contribute to making crayfish consumption safer as well.

\section{Conclusions}

In this work, the antibacterial activity of aqueous and ethanol extracts from Canadian goldenrod against three pathogenic bacteria common in crayfish aquaculture was evaluated. The effects of aqueous plant extracts supplemented in the crayfish diet on the activity antioxidant enzymes were also determined. The result indicates the potential for Canadian goldenrod to be a simple, economical and convenient dietary supplement to protect crayfish against infectious microorganisms and enhance their antioxidant defense system.

Acknowledgements This work was financially supported by Sanxin Project of Jiangsu Province, China (Y2015-19). We thank Prof. Huyin Huai, a plant taxonomist in College of Bioscience and Biotechnology, Yangzhou University, Jiangsu, China, for his help in the identification of the plants used in this study.

Compliance with ethics guidelines Manhong Ye, Lei Zhang, Jiaqi Ge, Haifeng Sun, Jingjing Ni, Shengmei Yang, and Wanhong Wei declare that they have no conflict of interest or financial conflicts to disclose.

All applicable institutional and national guidelines for the care and use of animals were followed.

\section{References}

1. Edgerton B F, Evans L H, Stephens F J, Overstreet R M. Synopsis of freshwater crayfish diseases and commensal organisms. Aquaculture, 2002, 206(1-2): 57-135

2. Provincial L, Guillén E, Alonso V, Gil M, Roncalés P, Beltrán J A. Survival of Vibrio parahaemolyticus and Aeromonas hydrophila in sea bream (Sparus aurata) fillets packaged under enriched $\mathrm{CO}_{2}$ modified atmospheres. International Journal of Food Microbiology,
2013, 166(1): 141-147

3. Lin C, Yu R C, Chou C C. Susceptibility of Vibrio parahaemolyticus to various environmental stresses after cold shock treatment. International Journal of Food Microbiology, 2004, 92(2): 207215

4. Tenover F C, Hughes J M. The challenges of emerging infectious diseases. Development and spread of multiply-resistant bacterial pathogens. Journal of the American Medical Association, 1996, 275 (4): 300-304

5. Villena A J. Applications and needs of fish and shellfish cell culture for disease control in aquaculture. Reviews in Fish Biology and Fisheries, 2003, 13(1): 111-140

6. Sheir S K, Osman G Y, Galal M A, Soliman M M. Biohazards of the biofungicide, Trichoderma harzianum on the crayfish, Procambarus clarkii: histological and biochemical implications. Egyptian Journal of Basic and Applied Sciences, 2015, 2(2): 87-97

7. Safari O, Shahsavani D, Paolucci M, Atash M M S. Single or combined effects of fructo- and mannan oligosaccharide supplements on the growth performance, nutrient digestibility, immune responses and stress resistance of juvenile narrow clawed crayfish, Astacus leptodactylus leptodactylus Eschscholtz, 1823. Aquaculture, 2014, 432: 192-203

8. Xu W N, Liu W B, Yang W W, Zhang D D, Jiang G Z. Identification and differential expression of hepatopancreas microRNAs in red swamp crayfish fed with emodin diet. Fish \& Shellfish Immunology, 2014, 39(1): 1-7

9. Xiao X C, Han D, Zhu X M, Yang Y X, Xie S Q, Huang Y. Effect of dietary cornstarch levels on growth performance, enzyme activity and hepatopancreas histology of juvenile red swamp crayfish, Procambarus clarkii (Girard). Aquaculture, 2014, 426-427: 112119

10. Safari O, Atash M M S, Paolucci M. Effects of dietary L-carnitine level on growth performance, immune responses and stress resistance of juvenile narrow clawed crayfish, Astacus leptodactylus leptodactylus Eschscholtz, 1823. Aquaculture, 2015, 439: 20-28

11. Huang H, Guo S L, Chen G Q. Reproductive biology in an invasive plant Solidago canadensis. Frontiers of Biology in China, 2007, 2 (2): 196-204

12. Yang R, Yu G, Tang J, Chen X. Effects of metal lead on growth and mycorrhizae of an invasive plant species (Solidago canadensis L.). Journal of Environmental Sciences, 2008, 20(6): 739-744

13. van Kleunen M, Ramponi G, Schmid B. Effects of herbivory simulated by clipping and jasmonic acid on Solidago canadensis. Basic and Applied Ecology, 2004, 5(2): 173-181

14. Bauer A W, Kirby W M, Sherris J C, Turck M. Antibiotic susceptibility testing by a standardized single disk method. American Journal of Clinical Pathology, 1966, 45(4): 493-496

15. Bradford M M. A rapid and sensitive method for the quantitation of microgram quantities of protein utilizing the principle of protein-dye binding. Analytical Biochemistry, 1976, 72(1-2): 248-254

16. Song Z F, Wu T X, Cai L S, Zhang L J, Zheng X D. Effects of dietary supplementation with clostridium butyricum on the growth performance and humoral immuneresponse in Miichthys miiuy. Journal of Zhejiang University Science B, 2006, 7(7): 596-602

17. Momot W T. Redefining the role of crayfish in aquatic ecosystems. Reviews in Fisheries Science, 1995, 3(1): 33-63 
18. Angeler D G, Sánchez-Carrillo S, García G, Alvarez-Cobelas M. S'anchez-Carrillo Salvador, Garc'1a G, Alvarez-Cobelas M. The influence of Procambarus clarkii (Cambaridae, Decapoda) on water quality and sediment characteristics in a Spanish floodplain wetland. Hydrobiologia, 2001, 464(1): 89-98

19. Scott J R, Thune R L. Bacterial flora of hemolymph from red swamp crawfish, Procambarus clarkii (Girard), from commercial ponds. Aquaculture, 1986, 58(3-4): 161-165

20. Brett F E, Louis H E, Frances J S, Robin M O. Synopsis of freshwater crayfish diseases and commensal organisms. Aquaculture, 2002, 206(1-2): 57-135

21. Rattan R S. Mechanism of action of insecticidal secondary metabolites of plant origin. Crop Protection, 2010, 29(9): 913-920

22. Apáti P, Szentmihályi K, Kristó S T, Papp I, Vinkler P, Szoke E, Kéry A. Herbal remedies of Solidago - correlation of phytochemical characteristics and antioxidative properties. Journal of Pharmaceutical and Biomedical Analysis, 2003, 32(4-5): 1045-1053

23. Letitia M M, Timothy J. Antioxidant activity in medicinal plants associated with the symptoms of diabetes mellitus used by the
Indigenous Peoples of the North American boreal forest. Journal of Ethnopharmacology, 2002, 82(2-3): 197-205

24. Xian Y F, Mao Q Q, Ip S P, Lin Z X, Che C T. Comparison on the anti-inflammatory effect of Cortex Phellodendri chinensis and Cortex PhellodendriAmurensis in 12-O-tetradecanoyl-phorbol-13acetate-induced ear edema in mice. Journal of Ethnopharmacology, 2011, 137(3): 1425-1430

25. Daniel C K, Lennox C L, Vries F A. In vivo application of garlic extracts in combination with clove oil to prevent postharvest decay caused by Botrytis cinerea, Penicillium expansum and Neofabraeaalba on apples. Postharvest Biology and Technology, 2015, 99 (1): 88-92

26. Wang X, Liu R, Yang Y, Zhang M. Isolation, purification and identification of antioxidants in an aqueous aged garlic extract. Food Chemistry, 2015, 187: 37-43

27. Wei K Q, Yang J X. Oxidative damage of hepatopancreas induced by pollution depresses humoral immunity response in the freshwater crayfish Procambarus clarkii. Fish \& Shellfish Immunology, 2015, 43(2): $510-519$ 